\title{
Perceptions of civil society on structured collaboration for improving the governance of adult education for poverty reduction
}

\author{
Olivia Adwoa Tiwaah Frimpong Kwapong \\ Bloomsburg University of Pennsylvania Visiting Fulbright Scholar (Associate Professor, University of Ghana) \\ Email address: \\ okwapong@ug.edu.gh,oliviakwapong@yahoo.co.uk
}

\section{To cite this article:}

Olivia Adwoa Tiwaah Frimpong Kwapong. Perceptions of Civil Society on Structured Collaboration for Improving the Governance of Adult Education for Poverty Reduction. Education Journal. Vol. 2, No. 4, 2013, pp. 119-126. doi: 10.11648/j.edu.20130204.13

\begin{abstract}
Adult educators work to alleviate poverty in developing communities. Proper management of available resources through an inter-sectorial coordinated approach contributes to widen access to interventions. A descriptive analytical survey among respondents from a developing country has revealed existence of some form of collaboration that could be enhanced by drawing a common budget for collaborative activities, using radio as a communication media, concentrating policy-making at the local level and building a coordinating team that is representative of all partners in development from the local beneficiary communities.
\end{abstract}

Keywords: Adult Education, Poverty Reduction, Developing Country, Civil Society, Collaboration, Governance

\section{Introduction}

There is a positive relationship between adult education, collaborative governance and poverty reduction $[1,2,3,4,5$, $6,7,8]$. Adult education has been found to be a useful tool for poverty reduction. Adult education programmes that that are managed from collaborative efforts is a sure way of utilizing limited resources for sustainable interventions in developing countries. Since the pre-colonial era various governments in Africa for instance have used adult education to build the capacity of its people for democratic governance and socio-economic development. Countries that have experienced war have also used adult education to reconstruct their nations. Impact has been great but much still leave to be desired. The limited resources of the developing world make it crucial to adopt a strategy that will make adult education interventions widely accessible to all citizens, most importantly the deprived and marginalized $[9,10]$. The views of civil society in Ghana were solicited to find out their thinking on collaborative opportunities among adult educators for addressing issues of poverty.

\section{Method}

A descriptive analytical survey was undertaken using a structured survey instrument. Data was collected from staff of the National Commission for Civic Education (NCCE) and civil society to find out their views on possible enhanced collaboration for adult education that will facilitate poverty reduction. NCCE is an independent, non-partisan governance institution that is set up under Article 231 of the Constitution of the Republic of Ghana to promote and sustain democracy and undertake civic education to create awareness among the adult population about their rights and responsibilities. The civil society comprised private media persons, non-governmental organisations, religious organisations and other individuals. Civil society is used in the paper to refer to all organisations and individuals that are independent of the government. Such individuals and groups operate privately and are expected to express their independent minds objectively. The World Bank (2013) broadly defines civil society as "the wide array of non-governmental and not-for-profit organisations that have a presence in public life, expressing the interests and values of their members or others, based on ethical, cultural, political, scientific, religious or philanthropic considerations. Civil Society Organisations (CSOs) therefore refer to a wide of array of organisations: community groups, non-governmental organisations (NGOs), labour unions, indigenous groups, charitable organisations, faith-based organisations, professional associations, and foundations". Per the 
definition of the World Bank, civil society seeks the interest and will of the masses. The views of staff of NCCE was solicited in addition to civil society because as an organisation, the NCCE work a lot with civil society to empower them for democratic governance and poverty reduction through adult educational interventions.

The instrument for data collection covered the profile of the participants as in the sex, age, and years of work experience, their institutions and possible collaborating agencies for adult educational activities. The nature of collaboration that is in existence in terms of human and material resources that they share, the issues that are dealt with and the existence of budget for this purpose were also assessed. To link them to the intended purpose of the study, the perceptions of the respondents were explored to find out their intentions towards a more intense inter-sectorial collaboration. In line with this the respondents were questioned on the communication media that will be most appropriate and appreciable, constitution of such a team, possibility of a common budget for common adult education activities, anticipated challenges and suggestions for collaboration.

\section{Results}

\subsection{Profile of Respondents}

Responses were received from 29 staff of NCCE and 157 members of civil society making a total of 186 respondents from Ghana. Out of the total number of NCCE staff 58.6\% were males with the remaining $37.9 \%$ being females. For the civil society respondents, $77.1 \%$ were males and $17.8 \%$ were females. A few did not indicate their sex. The ages of the respondents from NCCE ranged from below 29 to 59 years. Age 60 is the time for compulsory retirement so none of the respondents were of that age. The civil society were below 29 to 60 years plus. Majority of all the respondents were however below 29 to 39 years. These people form the cream of their organisations and society so their willingness to promote an enhanced collaboration for poverty reduction through adult education will be very hopeful for the future. All the respondents had attained formal education. The majority of them had studied up to the tertiary level. Table 1 presents details of the background of all the respondents of the study.

In terms of position, rank or status at their workplaces, the respondents from NCCE included administrative staff, civic education officers, field staff, public educators, chief executive officers and accounts personnel from all Regions in the country. The members of civil society were private radio presenters, directors of organisations in the regions, librarians, religious leaders and students from all over the country. As shown in Figure 1 all the respondents had worked for less than one year to over nine years. Majority of them had built a career for four years and over. These long years of service will possibly give them adequate experience for knowledge sharing on how to build enhanced inter-sectorial partnership for poverty reduction through adult education.

Table 1. Background of Respondents

\begin{tabular}{|c|c|c|c|}
\hline Institution & Sex & Frequency & Percentage \\
\hline \multicolumn{4}{|c|}{ Sex of Respondents } \\
\hline \multirow[t]{5}{*}{ NCCE } & male & 17 & 58.6 \\
\hline & female & 11 & 37.9 \\
\hline & Total & 28 & 96.6 \\
\hline & system missing & 1 & 3.4 \\
\hline & & 29 & 100 \\
\hline \multirow[t]{5}{*}{ Civil Society } & male & 121 & 77.1 \\
\hline & female & 28 & 17.8 \\
\hline & Total & 149 & 94.9 \\
\hline & system missing & 8 & 5.1 \\
\hline & & 157 & 100 \\
\hline \multicolumn{4}{|l|}{ Age Ranges } \\
\hline Institution & Age Ranges & Frequency & Percentage \\
\hline \multirow[t]{5}{*}{ NCCE } & Up to 29 & 9 & 31 \\
\hline & $30-39$ & 13 & 44.8 \\
\hline & $40-49$ & 5 & 17.2 \\
\hline & $50-59$ & 2 & 6.9 \\
\hline & Total & 29 & 100 \\
\hline \multirow[t]{8}{*}{ Civil Society } & Up to 29 & 67 & 42.7 \\
\hline & $30-39$ & 48 & 30.6 \\
\hline & $40-49$ & 17 & 10.8 \\
\hline & $50-59$ & 7 & 4.5 \\
\hline & $60+$ & 1 & 0.6 \\
\hline & Total & 140 & 89.2 \\
\hline & system missing & 17 & 10.8 \\
\hline & & 157 & 100 \\
\hline Institution & Educational Levels & Frequency & Percentage \\
\hline \multirow[t]{5}{*}{ NCCE } & middle/junior high & 4 & 13.8 \\
\hline & secondary & 1 & 3.4 \\
\hline & tertiary & 20 & 69 \\
\hline & other & 4 & 13.8 \\
\hline & Total & 29 & 100 \\
\hline \multirow[t]{7}{*}{ Civil Society } & middle/junior high & 57 & 36.3 \\
\hline & secondary & 5 & 3.2 \\
\hline & tertiary & 72 & 45.9 \\
\hline & other & 5 & 3.2 \\
\hline & Total & 139 & 88.5 \\
\hline & system missing & 18 & 11.5 \\
\hline & & 157 & 100 \\
\hline
\end{tabular}

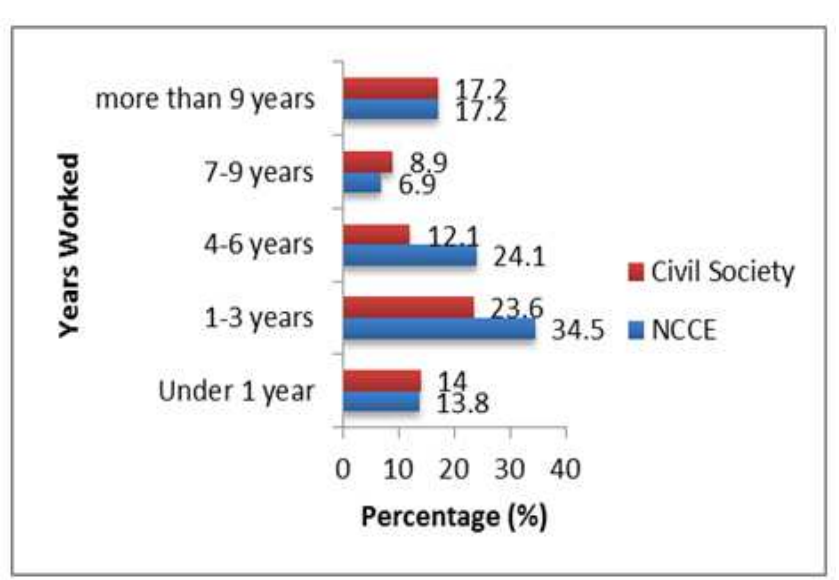

Figure 1. Years of Work Experience of NCCE Staff and Civil Society 


\subsection{Collaboration for Adult Citizenship Education and more}

Respondents were asked to share their experiences of collaborative adult education interventions in their communities. This was to have an idea of the current practices on the ground which could serve as a springboard for improved subsequent collaborative adult citizenship educational activities. The respondents from NCCE who are engaged in nationwide adult citizenship educational activities indicated that their educational activities focus on rights and responsibilities, peace and voter education. They indicated in their responses that they collaborate with various organisations for resource persons, field work assistance and logistic support. Among the organisations that they indicated to collaborate with included Ministries, Departments and Agencies (MDAs) and non-profit organisations like UNICEF, UNDP, DANIDA, CIDA, GTZ, Action Aid, World Vision, Plan Ghana, Youth Alive and various community-based organisations. The respondents from civil society indicated that in their various organisations they collaborate with varied organisations as and when it becomes necessary. Some of the organisations they mentioned include development agencies, security agencies, information services department, lands and forestry department, law agencies, telecommunication organisations and school boards.

Participants of the study shared the benefits that they had derived from the collaborative relationships. Respondents from NCCE and civil society noted that the collaborative relationships had helped them to undertake research on issues of concern, educate the public on their rights, civic responsibilities, and peaceful elections, adoption of new technologies for increased productivity, business development and living a healthy lifestyle. Other benefits that have been gained from collaborative activities include procurement and distribution of relief items during disaster such as heavy rainfall, evaluation of projects, constitutional education, skill improvement training, labour education to employers and employees, toilet facilities for schools, human rights education, dispute settlement and legal advice, micro credits for women, supply of books, news broadcast, public information circulation, healthcare delivery, education on land title registration and information on code of conduct. Some of the logistics support that respondents indicated to have received from collaborative relationships included fuel for field visits, training equipment, motor bikes and medication for the needy. This information helps to know that some form of collaboration exists which can be nurtured for a much deeper and structured relationship.

\subsection{Enhanced Collaboration for Poverty Alleviation through Adult Education}

The existence of some form of collaboration could be a nurturing ground for growing a deeper relationship for poverty alleviation using adult education interventions. In response to the question whether they anticipate an intense collaboration for poverty alleviation through adult education interventions, the results showed that majority of the respondents responded in the affirmative. Only $3.4 \%$ of the NCCE respondents and $14 \%$ of the civil society responded in the negative. To probe further their stake on the proposal for enhanced collaboration for adult education for poverty reduction, respondents were made to indicate the usefulness of such collaboration. They were to show whether the inter-sectorial collaboration will be very useful, useful or not useful. In response, none of the respondents from NCCE said it was not useful. Only $4.5 \%$ of the civil society said it will not be useful with $0.6 \%$ responding that there should be no coordination. The rest of the respondents were all in favour of enhanced and more formalized inter-sectorial collaboration for poverty reduction through adult education. Figures 2 and 3 present the detailed responses.

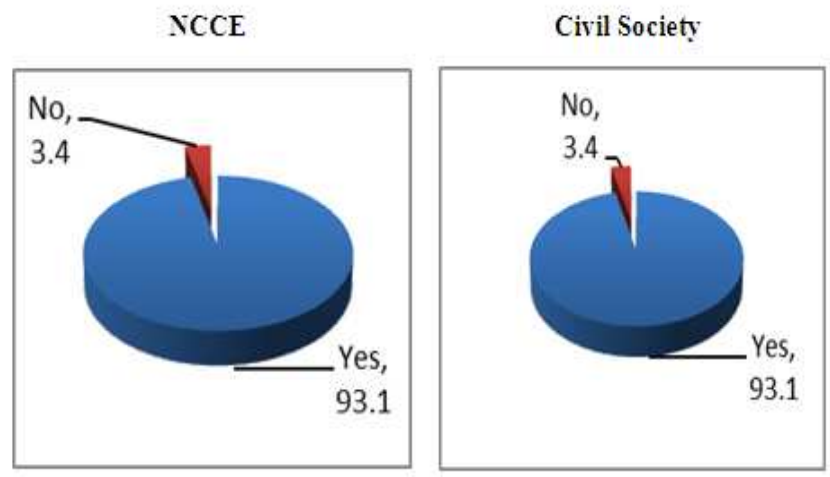

Figure 2. Deeper Collaboration for Poverty Alleviation

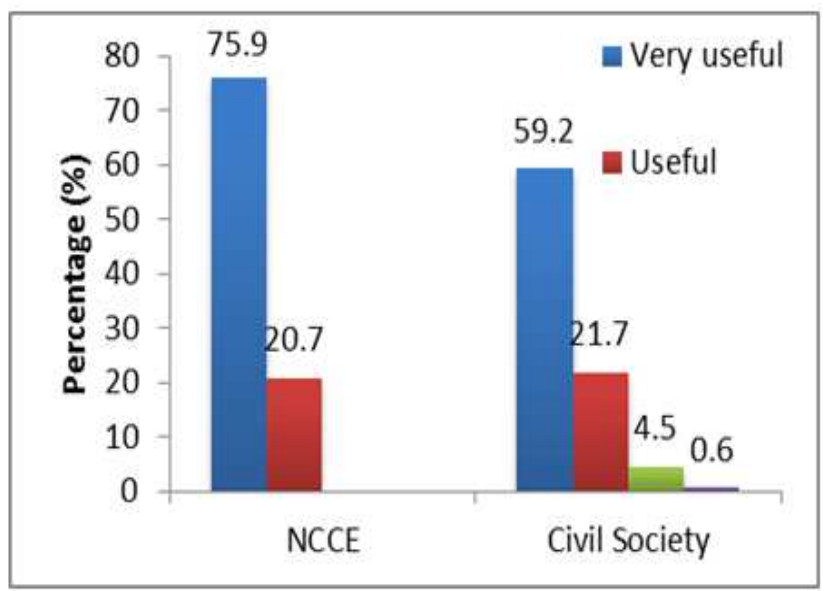

Figure 3. Usefulness of Collaboration

Several reasons were given for the massive positive responses. Respondents felt that enhanced inter-sectorial collaboration will help to pull resources together for a common activity and thereby reduce duplication, capacity building of the people will be enhanced due to proper utilization of the available resources and a combined effort with the indigenes will also facilitate cooperation. Some of their responses have been listed below: 
- Collaborating with others to champion some ideas makes it easier

- The coordination of agencies will strengthen education to alleviate poverty

- Combining effort with people who are familiar in the area they can facilitate cooperation

- $\quad$ This will help reduce social vice such as stealing, raping and drug addiction

- Will boost the economy

- To build capacity through training, to improve standard of living

- With the involvement of more adult educators, the natives readily accept information and skills

- Because lack of knowledge breeds poverty

- $\quad$ Because of the different professional capability. It allows for team and information sharing to help eradicate poverty

- So that more people in the rural areas can be educated

- The community can be given skill training programmes to meet the challenges of the present day

- So that we can use combined effort to provide the people with the right skills and attitude to work

- We can assist persons without education to know their right... also source funds for the needy adults to go into income generation

- It is important because poverty is the greatest enemy on earth and it must be eradicated with the involvement of all stakeholders

- Sometimes the outfit of NCCE collaborate with the ministry of education to educate parents on the need to send their wards to school

- This is because they will pull resources together to help reduce the illiteracy rate in the country through education

- Working together would make the work easier

- $\quad$ Adult educators would complement each other's efforts

- There will be better implementation of policies

- Because there will be dissemination of information into the communities

- Because adult educators normally promote the important of alleviating poverty in the country

- Ignorance and lack of skills are some of the causes of poverty. With adults educators collaborating to build the capacities of the people and creating awareness to a larger extent alleviate poverty among the people

- $\quad$ Resource will be effectively utilized and duplication of effort will be avoided and synergies enhanced thereby promoting efficiency and impact of interventions

- So that we can have more literates to constitute the working force

- The reason is that when adult educators work closely and effectively together in rural communities it would alleviate poverty in that the education make the rural folks to change their way of thinking and primitive lifestyle that is counterproductive

- These will bring a strong collaboration to improve their standard of living and eradicate poverty

- $\quad$ They can form adult education groups in the various community and assist them with small loans

- This is because adult educators are well experienced to impact positively on their trainees to alleviate poverty

- This will help to promote full participation of the people involved (bottom-up approach)

- $\quad$ To alleviate the problems of high dependency ratio on the working population

- Together we can

- With the adult educators working together in communities we can educate rural folks to realize their potential resources

\subsection{Organizing for Enhanced Collaboration}

The study also sought to find out from respondents their views on modalities for establishing structured collaborative systems for adult education for poverty reduction. They were interviewed on the centre of decision-making, budgeting, media use and proposed composition of a coordinating team.

The concentration of decision-making power for adult education interventions that seek to alleviate poverty has implications for the sustainability of interventions $[11 ; 12$; 13]. On the concentration of decision-making power, respondents were asked to rank where decision or policy making for enhanced inter-sectorial collaboration for adult education for poverty alleviation should be concentrated most - from communal level to international level. The concern was considering the allocation of decision-making to communal, district, national and international levels, how should the ranking be? One was the highest rank and four the lowest. Their rankings are presented in Figures 4a, $4 \mathrm{~b}, 4 \mathrm{c}$, and $4 \mathrm{~d}$.

In terms of decision-making at the communal level, majority of the NCCE staff (34.5\%) gave it a third ranking with equal percentage $(20.7 \%)$ giving it a first (highest) and fourth (least) ranking. Majority of the civil society on the other hand ranked decision-making at the communal level very highly (26.1\%). Comparatively, while majority of civil society prefer that decision-making should be resided at the communal level, respondents from the Government's side (NCCE) think differently (Figure 4a). Thus while the people want power to remain with them at the community level, the technocrats think otherwise. Could this be a reason for inability to make citizens take ownership of adult education interventions that will possibly lead to sustainability? Will this kind of attitude promote effective implementation of the decentralization concept? Since government institutions may not be committed to implementing adult education poverty reduction programmes in such a way that there will be total civil society participation that will lead them to own the intervention.

The ranking of decision-making at the district assembly level followed a similar trend with minimal variation. Much as the country is committed to the decentralization governance system, responses in Figure $4 \mathrm{~b}$ show that majority of the NCCE staff ranked the concentration of decision-making at the district assembly second. Majority of the civil society who probably believe in the district assembly concept ranked it first (19.1\%) and second (24.8). compared to $2.7 \%$ of the NCCE staff who ranked decision-making for adult education for poverty reduction at the district assembly level fourth, only $4.5 \%$ of the civil society ranked it fourth.

The results of the ranking of decision-making at the national level showed that majority of the respondents from NCCE preferred it to be cantered at the national level. Only $3.4 \%$ ranked the concentration of decision-making at the 
national level fourth. All the rest ranked it from first to third with the majority, $34.5 \%$ giving it a first ranking. The responses of the civil society also followed a similar trend though only $11.5 \%$ gave decision-making at the national level second ranking (Figure 4c).

Generally, both respondents from NCCE and civil society did not give high rankings to centralization of decision-making or policies for promoting collaboration for adult education interventions for poverty reduction at the international level (Figure 4d). Obviously, the respondents felt that countries or nationals should be responsible for and take ownership of their own poverty reduction initiatives instead of being donor-dependent or looking up to international bodies and regulations. From the results, more than half $(55.2 \%)$ of respondents from NCCE and almost a quarter $(24.2 \%)$ of the civil society who responded to that item gave the least (fourth) ranking to concentration of decision-making for use of adult education for poverty reduction at the international level.

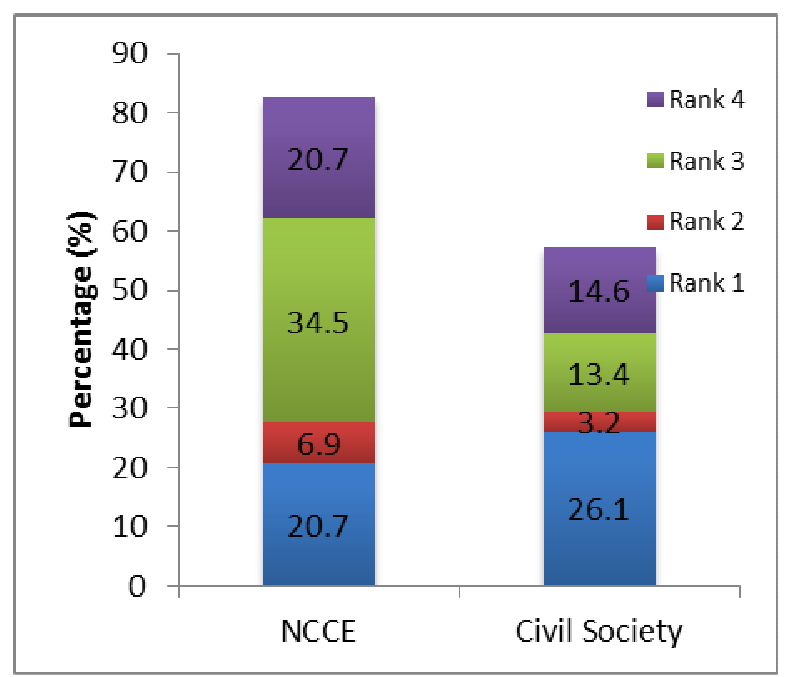

a. Ranking of Communal level Decision-making

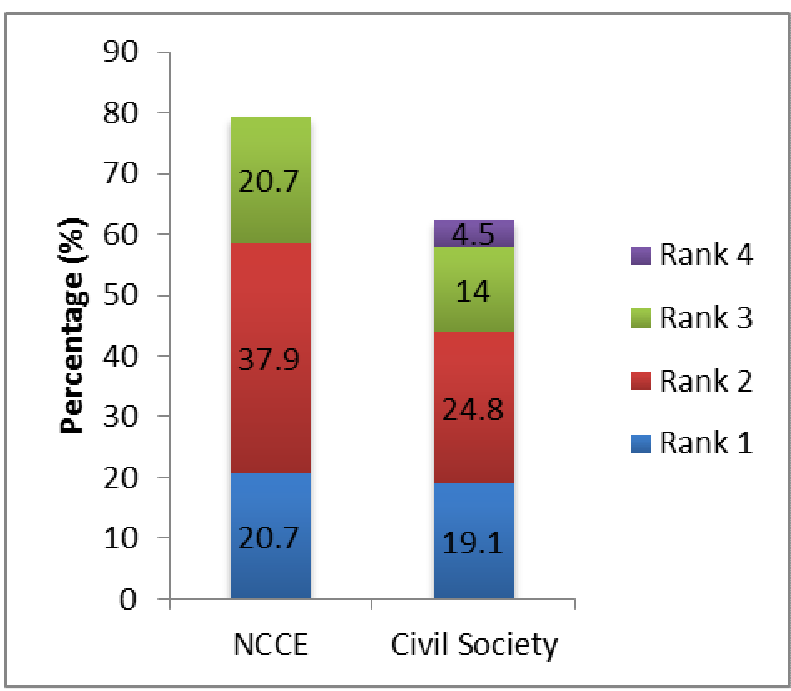

b. Ranking of District-Assembly level Decision-making

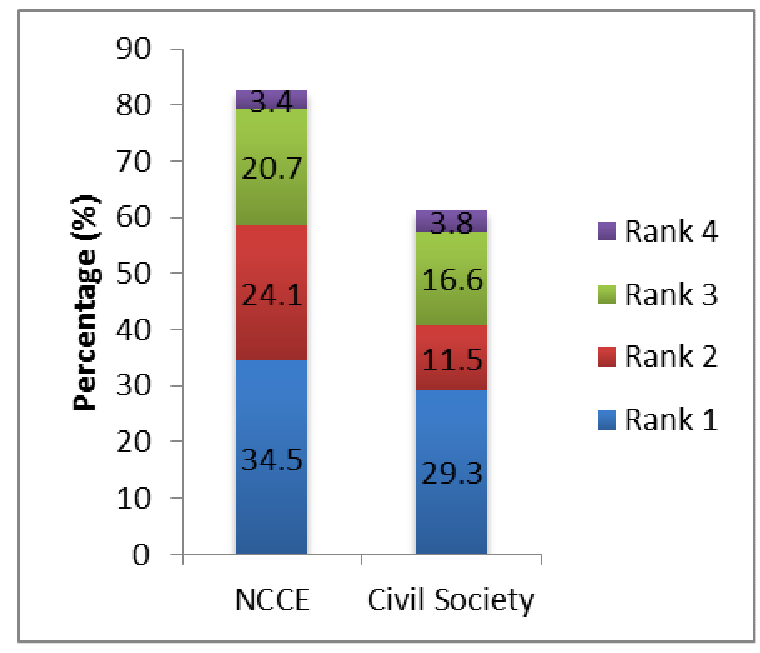

c. Ranking of National level Decision-making

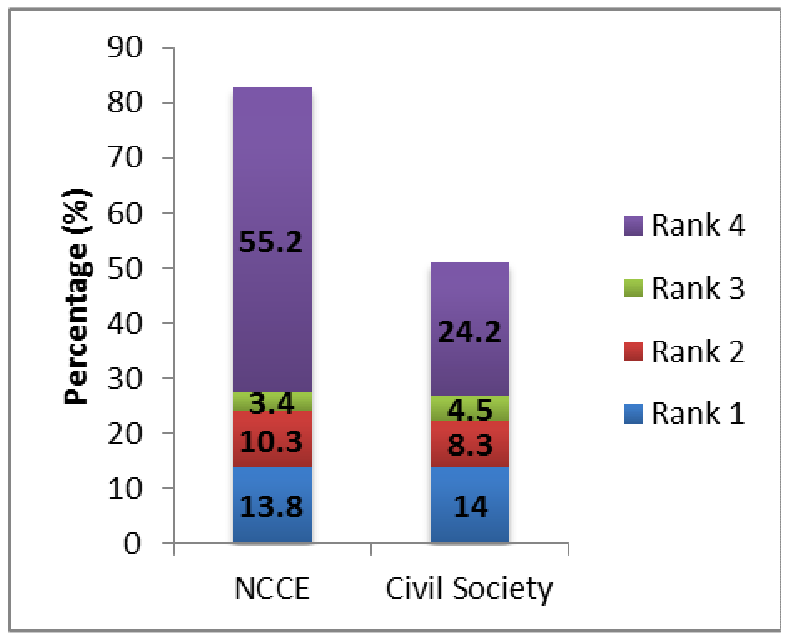

d. Ranking of International level Ranking Decision-making

Figure 4. Ranking of Levels of Decision-making

A way of testing the possibility of commitment to deeper inter-collaborative support for adult educational activities for poverty reduction was to find out whether there is budget for it. Under the financial control model of the concept of inter-locking directorate, He (2010) has noted that budget is 'the core of the corporate control because corporate finance is the focus of all parties' interest' (pp. 217). Responses from the survey in Figure 5 showed that only a few of the respondents $(27.6 \%$ of the NCCE staff and $20.4 \%$ of civil society) knew that their organisations had budgeted for collaborative activities. This means that much as majority of the respondents are in favour of deeper inter-sectorial collaboration for poverty reduction through adult education, there is no much financial commitment yet. This will be an area that will require intense orientation when making steps to build strong inter-sectorial collaboration for poverty reduction through adult education. The few who responded that there is budgetary allocation for adult educational collaborative activities in their organisations were asked to indicate what the budget lines were. Their responses covered budget for community 
education on government policies, radio discussions on topical issues, research activities, capacity building workshops, public education on topical issues such as road accident, governance, human rights and healthy living and for improving the living standard of the deprived communities. All the budget items that were mentioned are part of the core mandate of the organisations but not direct inter-sectorial mobilization activities. One could thus conclude that the institutions are yet to have in their budget resources assigned for inter-sectorial mobilization activities for poverty reduction through adult education. In his paper on Getting Agencies to Work Together Bardach (1998) has argued under the 'craftsmanship theory' that the mere existence of communication networks does not guarantee productivity and success. The actors of the network have to be competent and motivated to produce. The craftsmanship theory is dependent on capacity to succeed. In effect there should be quality human and social resources, smart practices, critical skills and ability to stand above threats that emerge. One will thus expect that budget for strengthening inter-sectorial bodies should target capacity building and motivation for members to bond, commit and direct the network but not individual organisational activities.

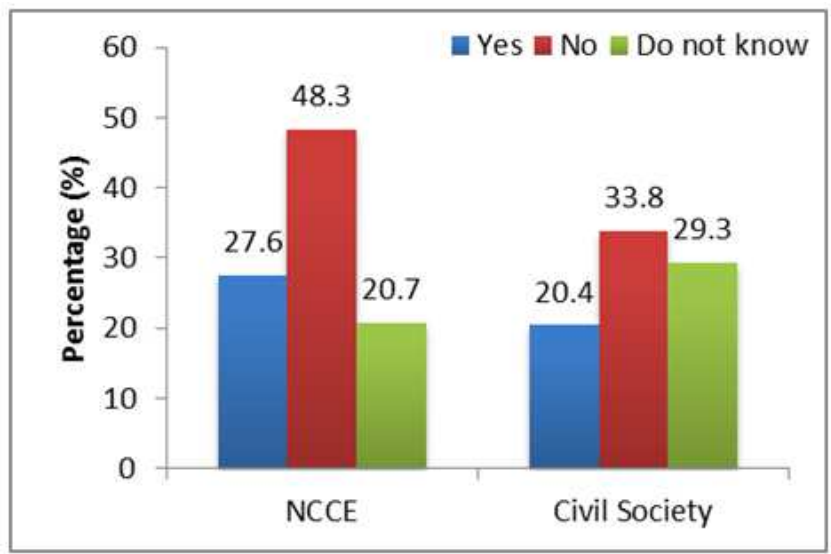

Figure 5. Allocation of Funds for Collaborative Activities

Media forms a very critical part of an adult education provision in general and for poverty reduction in particular in two major ways. First as a means of building the network and second as an approach for providing adult education interventions to the target population $[14 ; 15]$. The respondents were questioned on how they will rank the preference of print materials, radio and television for adult education collaborated activity for poverty reduction in a developing country in particular. In response, radio emerged as the highly ranked among all the media by $45.2 \%$ of civil society and 58.6 of the staff of NCCE (Figure 6). Radio continues to gain prominence in adult education provision in general and connection of sectors for developmental activities such as poverty reduction in developing worlds. As a very historic media, the easy accessibility and connectivity, versatility, affordability, user-friendliness and the current emerging growth of interactivity of radio with the support of mobile telephony and internet continue to make it stand the test of time. In the face of the internet revolution, users of radio continue to increase at an alarming rate especially in developing countries which continue to experience proliferation of FM radio stations for political, agricultural, health and socio-economic adult educational activities $(16,17)$. The Radiocommunication sector of the International Communication Union (ITU) [18] has acknowledged that the sector is witnessing a phenomenal increase in a myriad of applications. It is therefore not surprising that the respondents of the survey listed radio as the most preferred media for their collaborative activities and adult education interventions for poverty reduction.

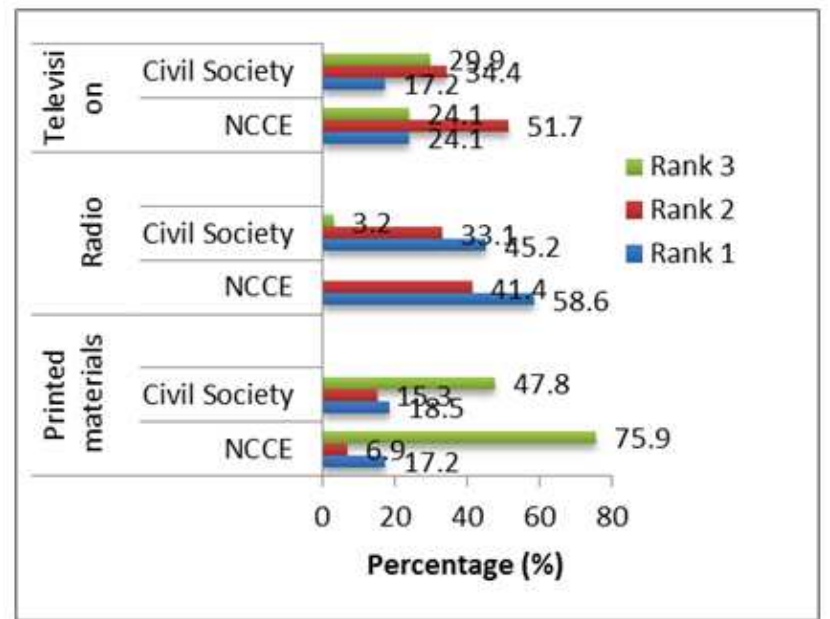

Figure 6. Ranking of Media for Inter-sectorial Coordination and Programme Delivery

Who should form part of a team of sectors for coordinating adult education interventions for poverty reduction should be a concern if sustainability has to be achieved $[3,4]$. The composition of the team was therefore explored among the respondents. Respondents proposed that the teams for inter-sectorial collaboration for adult education for poverty reduction could comprise all organisations that undertake adult educational activities such as agricultural extension agents, health extension workers, research institutions, human rights activists, civic education institutions, regional and district councils, disability associations, farmers associations, women's groups, local authorities, security agents, disaster relief agencies, opinion leaders in communities, traditional rulers, drama groups, community support groups. non-profit organisations and ministries. Adhering to these proposals from the respondents could go a long way to build trust in the team that will be composed. One assurance that parties need to sustain a collaborated relationship is trust $[15,18$, 20, 21]. Jacobsen [15] strongly supports other studies in emphasizing the importance of trust and consensus in networks. For Smith [20] the absence of personal factors likes trust contributes to the underperformance of most networks. 
In their final remarks, all the respondents were asked to offer suggestions for building a strong inter-sectorial collaboration for poverty reduction through adult education. Very useful suggestions were made to this effect. Per the views outlined below, the issue of training of all partners of the collaboration, involvement of women, setting clear targets, provision of required resources and incentives for motivation were among the suggestions that respondents made for building a strong inter-sectorial team for poverty reduction through adult education.

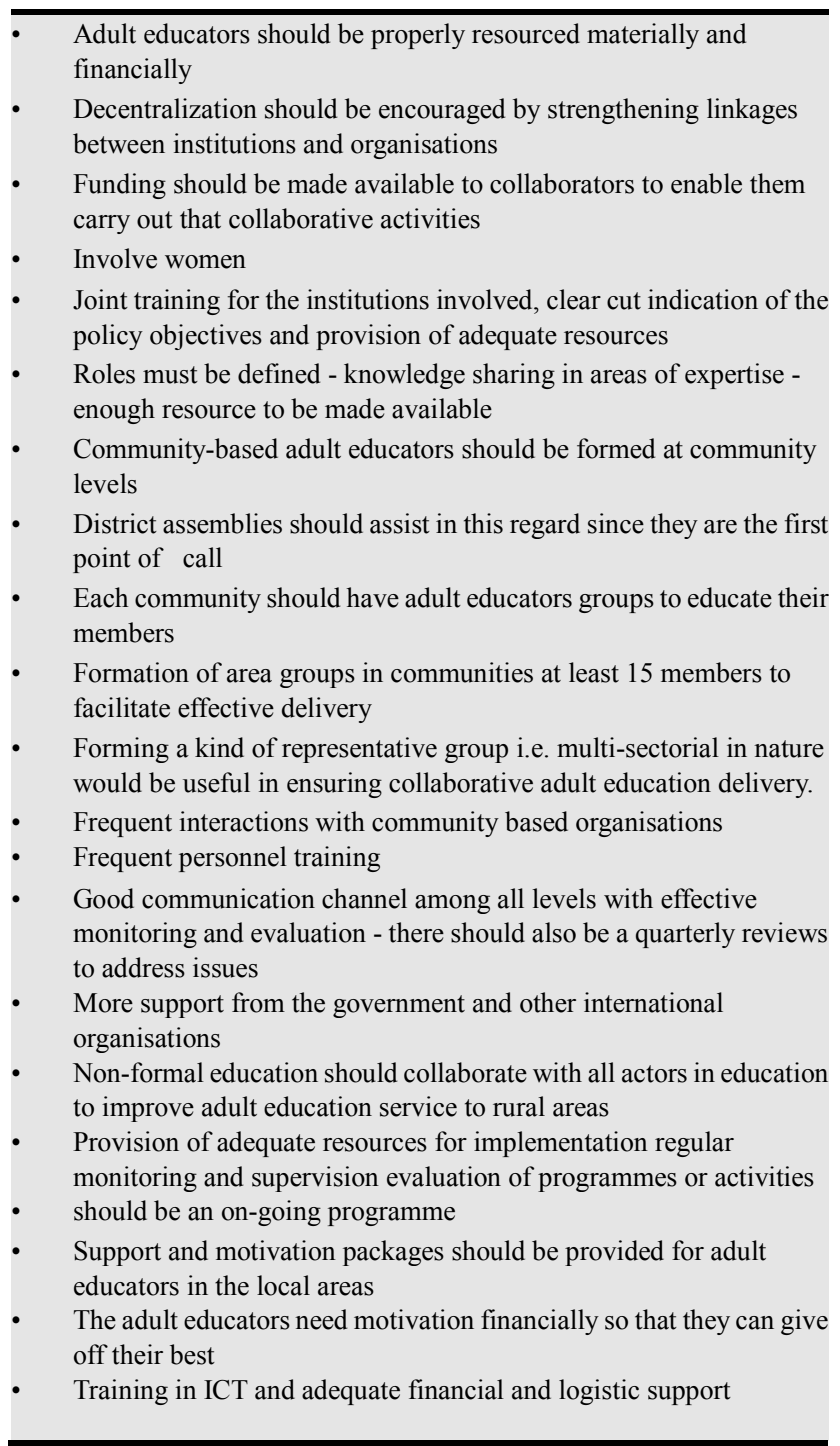

\section{Conclusion}

Effective coordination of adult education interventions contributes to poverty alleviation in developing communities in particular. Civil society and public institutions have a stake in the use of adult education for poverty reduction. Description survey in a developing country such as Ghana has revealed the views of civil society and public personnel on considerations for coordinating adult education interventions for poverty reduction. There was evidence of collaborative efforts which could serve as a springboard for intense inter-sectorial collaboration for poverty reduction through adult education. The respondents reported that they undertake adult education activities such as citizenship education, skills training and use of new technologies for business development, healthy living techniques and other skills for life. They collaborate to share resource persons for training programmes, undertake research activities, provide tools for training and solicit office supplies. Though there was no evidence of budget to support their claim, there was willingness for enhanced inter-sectorial collaboration for adult education for poverty alleviation. Radio was found to be a suitable media for both coordination purposes and delivery of adult education interventions. Much as members of the civil society were in favour of policy and decision making power distribution, respondents from the government's side were more in favour of concentration of decision-making at the national level. Remarkably, respondents wanted a team of coordinators that would be representative of stakeholders at the community level

\section{References}

[1] C. S. J. Hunter, and D. Harman, "Adult Illiteracy in the United States", A Report to the Ford Foundation, 1979.

[2] C. Duke, "Adult Education and Poverty: What Are the Connections?. Convergence: An International Journal of Adult Education, 1983, vol. 16, pp. 76-86.

[3] J. B. Tilak, (2002). "Education and poverty", Journal of Human Development, 2002, vol. 3, pp. 191-207.

[4] H. S. Bhola, "Adult and lifelong education for poverty reduction: A critical analysis of contexts and conditions", International review of education 2006 vol. 52, pp. 231-246.

[5] Wedgwood, R. (2007). Education and poverty reduction in Tanzania. International Journal of Educational Development, 27(4), 383-396.

[6] [6] J. Preece, R. van der Veen and W. Raditloaneng, "Adult Education and Poverty Reduction: Issues for Policy, Research, and Practice", Lentswe La Lesedi (Pty) Ltd. 2007.

[7] [7] S. Klasen (2008), "Economic growth and poverty reduction: measurement issues using income and non-income indicators", World development, 2008, vol. 36, pp. 420-445.

[8] M. Blaak, G. L. Openjuru and J. Zeelen, "Non-formal vocational education in Uganda: Practical empowerment through a workable alternative", International Journal of Educational Development, 2013, vol. 33, pp. 88-97.

[9] E. Bardach, "Getting Agencies to Work Together", Washington, DC, USA, 1998, Brookings Institution Press.

[10] S. Duryea, "Human Capital Policies: What They Can do and cannot do for Productivity and Poverty Reduction in Latin America", 2002.

[11] V. Adjiwanou and T, LeGrand, "Does Antenatal Care Matter in the Use of Skilled Birth Attendance in Rural Africa: A Multi-country Analysis", Social Science \& Medicine, 2013. 
[12] T. W. Valente, (2012). "Network interventions", Science, 2012, Vol.337, pp. 49-53.

[13] H. Gil de Zúñiga, N. Jung and S Valenzuela, S. (2012). "Social media use for news and individuals' social capital, civic engagement and political participation", Journal of Computer-Mediated Communication, 2012, vol. 17, pp. 319-336.

[14] L. He, (2010). "On financial control and corporate governance structure", International Journal of Business and Management, 2010, Vol. 5, pp. 215 - 218.

[15] Dag Ingvar Jacobsen, "The impact of governing networks-the role of context, organizing and trust", ISL Working Paper, 2012, Vol. 1.

[16] M. Lundin, (2007). "Explaining cooperation: How resource interdependence, goal congruence, and trust affect joint actions in policy implementation", Journal of Public Administration Research and Theory, 2007. Vol. 17, pp.
651-672.

[17] [17] O. A. T. F. Kwapong, "Equitable access - Information and communication technology for open and distance learning”, 2010, New York: iUniverse, Inc., pp. 260.

[18] International Telecommunication Union, "Radiocommunication Sector - Committed to connecting the world", Retrieved April 8, 2013 from http://www.itu.int/pub/R-GEN-OVW-2012

[19] L. Moyo, L. (2013). "The digital turn in radio: A critique of institutional and organisational modelling of new radio practices and cultures", Telematics and Informatics, 2013, vol. 30, pp. 214-222.

[20] Harriet L Smith, (2010). "Interpersonal trust and cooperative behavior in a strategic alliance", Doctoral dissertation, The George Washington University, 2010.

[21] World Bank, Defining civil society, 2013, Retrieved April 8, 2013 from http://go.worldbank.org/4CE7W046K0 